\title{
Stressors, Coursework Stress and Coping Strategies among Medical Students in a Private Medical School of Karachi, Pakistan
}

\author{
Darayus Percy Gazder ${ }^{1}$, Farah Ahmad ${ }^{2}$, Syed Hasan Danish ${ }^{2}$ \\ ${ }^{1}$ Fourth Year MBBS Student, ${ }^{2}$ Assistant Professor, Department of Community Health Sciences, Ziauddin \\ University, Karachi Pakistan.
}

$\begin{array}{ll}\text { ARTICLE INFO } \\ \text { Received } & : 25 / 04 / 2014 \\ \text { Accepted } & : 10 / 07 / 2014 \\ \text { Published } & : 01 / 09 / 2014\end{array}$

\section{KEYWORD}

Coursework

Wishful thinking

Problem solving coping

Stressor

\begin{abstract}
Objective: To evaluate stressors, coursework stress and coping strategies such as wishful thinking and problem solving coping among medical students. Method: A cross-sectional study was conducted in a private medical school of Karachi, Pakistan. A total of 240 students were selected through random sampling technique from first year to fourth year medical students. Validated questionnaires were used for data collection. Data was entered on SPSS version 20. Descriptive analysis was performed to report the frequency of stressors. Pearson correlation test was performed to test correlation between coursework stress and coping, independent t test was performed to test the mean difference of academic stressors on the basis of gender and ANOVA was performed to test the mean difference of stress and coping strategies scores between years of study, p-value less than 0.05 was considered as significant. Results: The mean (SD) age of the students was 20.98 (1.46) years. Majority of the students were females. In general, medical students frequently used wishful thinking and problem solving as coping strategies. Academic related stressors (mean=2.48, SD =0.82) were found to be predominant in all the years of study followed by social related stressor. Conclusion: Student who were frequently using the coping techniques seem to experience high level of coursework stress. Third year medical students were seen to be more stressed out, followed by fourth year students. Least amount of stress was seen in the first year. Academic requirements were found to be the most prevalent stressor.
\end{abstract}

(C) Medical Education Department, School of Medical Sciences, Universiti Sains Malaysia. All rights reserved.

CORRESPONDING AUTHOR: Darayus P. Gazder, 56 Katrak Parsi Colony, OFF MA Jinnah Road. Karachi,

Pakistan. Email: darayusthegreat@gmail.com

\section{Introduction}

Professional education has always been a source of stress for amateurs pursuing a degree in a competitive environment (World Health Organization, 1994) (1). Though it remains a top choice among undergraduates (2), medicine as compared to other professions has been regarded as a highly stressful environment. Studies conducted have highlighted that the medical training exert unwanted effects on physical and mental wellbeing of the students (2-6). The prevalence of psychological distress has been found to be in the range of 30 to $50 \%(3,6)$. 
Medical training is considered as the most challenging course as compared to other disciplines - anxiety and stress are considered as common consequences regardless of the admission process and the course duration (5). Multifarious factors like course content, lack of leisure time activity and dealing with suffering and death have been implicated with stress related to medical training (7). In addition, students are also facing the dilemma of cut throat competition, obligation to success and uncertain future (8). These stressors cause unnecessary physical, emotional and mental pressure leading to poor self-esteem and eventually compromised academic performance (9-11). In third world countries like Pakistan, India, Malaysia and Thailand, several studies conducted on this topic have avowed the association of stress with medical education $(12,13)$. A study conducted in Aga Khan University, Karachi further affirmed that $90 \%$ student's feel stressed out at one time or more during the 5 year course (12).

The importance of this association of stress with medical education has been the subject of apprehension for the medical academicians for more than two decades (14). Students on the other hand strive to develop techniques that can ease out the stress and make their student and professional life as a healthy experience (15). This was affirmed by a study conducted by Holahan \& Moos (1987) who emphasized upon the idea that people who do not handle their stressors tend to suffer from health problems (16).

Basically, coping with stress and managing it effectively is not merely as a result of the stressful event (i.e. stressor) but the individual's perception and emotional reaction to the stress. Lazarus (1991) and Folkman (1984) suggested there are two types of coping responses. The first is problem focused coping - which is directed towards an attempt to alleviate or eliminate stressful situations. People using problemfocused strategies try to deal with the cause of their problem. For example making a plan and following it. The second coping strategy is emotion focused (e.g., wishful thinking) which involves trying to reduce the negative emotional responses associated with stress. The person who is effectively managing their responses to the stressor will act appropriately according to the reality. Some people perceive stress as negative and coping as a positive, however the relation is not that simple. Stress can be psychologically positive or negative, and the means of coping can be effective or ineffective in meeting the challenge presented by the stressor.

In Pakistan, young generation constitutes almost $40 \%$ of the total population and medical students form an important section of this age group (17). Taylor (1998) echoed that stress among students, specifically medical students, have not been enthusiastically researched upon. Our study explored the prevalence and source of stress among a medical student community and also looked into the coping strategies adopted to deal with the problem. We evaluated different stressors and which stressor group has its maximum effect on the medical students. We investigated their perceived university coursework stress and which type of coping strategy is used by students under-stress, either wishful thinking or problem solving strategies. The strategy chosen is thought to be situation specific. In other words different coping strategies are employed according to the context of the stressor.

\section{Method}

The present study was undertaken at Ziauddin University. It was a one year project and a total of 240 medical students $(60$ student were selected from each year). Simple random sampling technique was employed for data collection. We carried out this survey in the middle of the semester to circumvent the stressful time of sessions and university examinations at the end of the semester. Inclusion criteria were all students from first year to fourth year who are studying at Ziauddin University inclusive of repeaters and transfer students. Exclusion criteria were those who failed to consent or were absent at the time of data collection. The nature of survey, applicability of results and confidentiality were explained to the participants. Completion of 
questionnaire was voluntary and affirmed that it would not affect the progression of their medical course. The questionnaires were distributed in face-to-face session in lecture hall separately according to the year of study. The students were informed to follow the instructions. Filling of questionnaires took approximately 20 minutes and students were advised to return it on the same day. Some questions with Likert-type responses, some multiple choice questions and few open ended questions were filled by the students. Clearance was taken from the ethical review board prior to the start of study. The study was done with the perusal of the head of the institution and then informed consent was taken from participants.

Data was collected using a questionnaire consisting of three parts: (i) socio-demographic questions, (ii) questions designed to elicit information about the sources and levels of stress and (iii) a validated instrument to measure coping strategies.

\section{Medical student stressor questionnaire (MSSQ)}

MSSQ was used to measure six stressors affecting students and has 20 items (19). The Medical student stressor questionnaire was developed to identify the stressors of medical students as well as measure the intensity of stress caused by the stressors. The Cronbach's alpha value of the MSSQ was 0.92. Composite Reliability and Average Variance Extracted values of the six stressors were more than 0.6 and 0.5 respectively indicating good construct reliability to identify stressors. For each potential stressor 5 categories were placed and classified as causing no stress at all, causing mild stress, causing moderate stress, causing high stress, causing severe stress to indicate intensity of stress caused by these items. Recommended scoring method of zero for least intensity of stress and maximum of four for most intensity of stress was used (i.e. scale of $0,1,2,3,4)$ as was done by previous studies (20).

\section{Revised Way of Coping Checklist:}

The Ways of Coping Checklist (revised in 1985), is an empirically derived inventory composed of problem focused and emotion focused items (confrontive coping, distancing, self-controlling, seeking social support, accepting responsibility distancing, self-controlling, seeking social support, accepting responsibility, escapeavoidance, problem-solving and positive reappraisal (21).The ways of coping checklist measures particular ways in which individuals might cope with a stressful episode in their life (31). This test directly was used to assess coping styles used by medical students and whether the use of wishful thinking or problem-focused coping is related to stress in medical students. The revised Ways of Coping differs from the original Ways of Coping Checklist (21) in several ways. The response format in the original version was Yes/No; on the revised version the subject responds on a 4-point Likert scale $(1=$ never used; $4=$ always used). The revised way of coping checklist which consisted of 66 questions was altered to fit into the context of our research investigation. It comprised of 15 questions that were directly pertaining to coursework stress and coping mechanisms being used by medical students.

\section{Coursework Stress Management}

This part was based on questionnaire designed by Ann-Marie Roy (2003) (22). It comprised of 11 questions and measured the stress levels in completing the coursework. Each item was rated in terms of degree of apprehensiveness or concern from strongly disagree (1) to strongly agree (5). The total score was the sum of all scores - high scores reflect high stress.

The data was collected, verified by hand, tabulated, fed into Microsoft excel explored and cleaned for double entry errors and later analyzed by using SPSS version 20. Descriptive statistics were calculated for severity of sources of stress and coping strategies. Mean and standard deviation were taken out for stressor scores. Percentage frequency of occurrence was calculated for each of the stressors. Independent 
sample $\mathrm{t}$ test was performed to test the mean difference of academic stressors on the basis of gender. After checking the assumptions, ANOVA was performed to test the mean difference of stress and coping strategies scores between years of study. Significant level was set at alpha $(\alpha) 0.05$ (confidence interval of 95\%).

\section{Result}

The study results focused on a total of 240 medical participants, comprising of 60 students each from first, second, third and fourth years. The demographic profile of overall sample is shown in Table1. Mean age of the students was 20.98 (standard deviation $=1.46$ ). About 145 students were females $(60.4 \%)$, as 95 were male $(39.6 \%)$. Their ages were between 18 to 27 years.

Table 1: Demographic profiles

\begin{tabular}{lccccc}
\hline Year of Study & Male & Percentage & Female & Percentage & Total (N) \\
\hline First & 19 & 31.7 & 41 & 68.3 & $60(100 \%)$ \\
Second & 27 & 45.0 & 33 & 55.0 & $60(100 \%)$ \\
Third & 27 & 45.0 & 33 & 55.0 & $60(100 \%)$ \\
Fourth & 22 & 36.7 & 38 & 63.3 & $60(100 \%)$ \\
& & & & & 240 \\
\hline
\end{tabular}

\section{Current Coursework Pressure}

When different medical years were taken into account regarding current coursework pressure, third years $n=10(16.7 \%)$ were found to be under maximum coursework pressure as compared to other years. Likewise when course work stress was compared with different years, third years scored the maximum (Figure 1).

\section{Coping Strategies Employed}

Two coping traits or strategies were further analysed against the perceived coursework stress i.e. wishful thinking and problem focused coping. It was seen that overall medical student's use wishful thinking coping and problem solving coping almost equally. Graphically, in individual years of study it was seen that wishful thinking was more common among the first year students (Figure 3) and problem focused coping among the fourth years was the greatest (Figure 4). Ironically coping strategies among third years were found to be the least comparing to the course work stress they encounter (Figure 2).

Identifying medical school stressors and their intensity in different years of study as already identified in the methodology all six stressors were found to directly impact the students. Academic related stressor with a mean of 2.48 is the primary stressor among medical school students. Social related stress with a mean of 1.69 is the next major stressor. Drive related stressor was the least significant stressor among all. Group activity related stressor at 1.66 was found to be next on the list and can be described as stress arising in students when working among their peers (Table 2, 3, Figure 5)

When ARS was stratified according to gender, significant difference was observed ( $p$ value 0.05 ) and females were found to endure more academic related stress. When difference among medical years was assessed through ANOVA, maximum ARS was found in first year followed by fourth year ( $p$ value 0.001 ). Post hoc test was applied for finding difference between the groups and significant difference was observed between first years and second years ( $p$ value $0.000)$.

When the extent of pressure was asked from the students in meeting course work deadlines in their present modules, significant difference was found among males and females where $n=131$ 
(92\%) females were found to be under great deal of pressure as compared to $\mathrm{n}=75(79 \%)$ males $(\mathrm{p}$

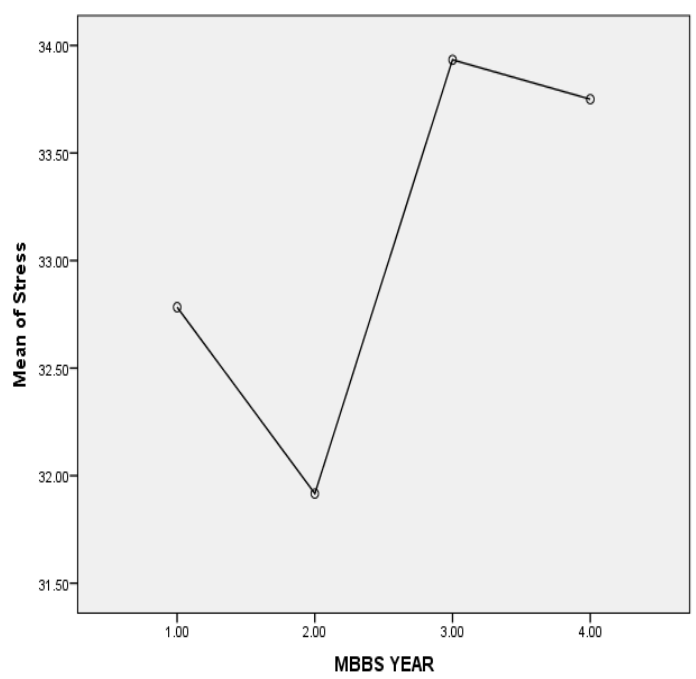

Figure 1: Perceived coursework stress

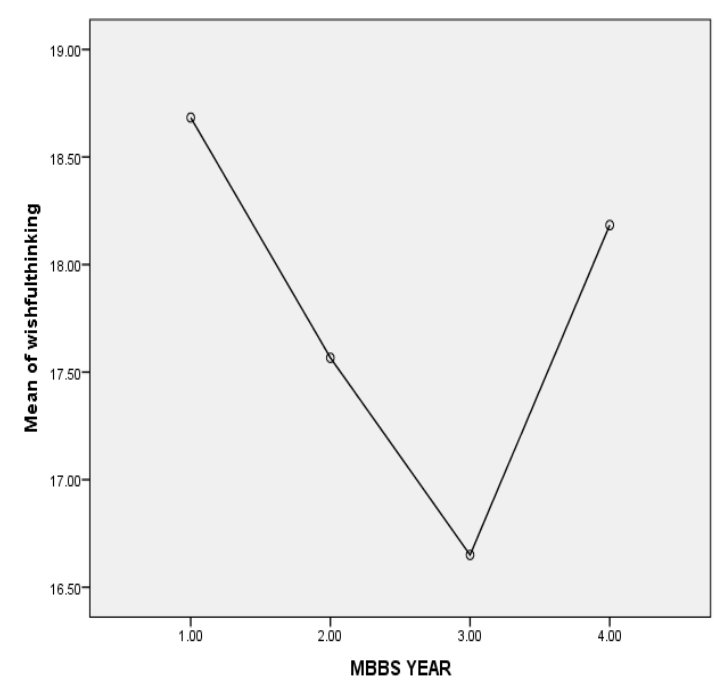

Figure 3: Wishful Thinking Coping Employed in different years of study value 0.04$)$.

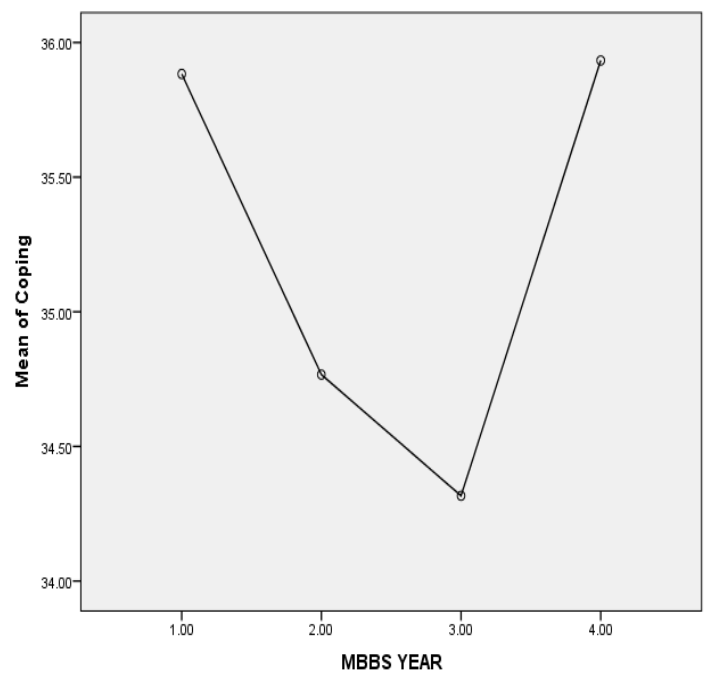

Figure 2: Coping mechanisms employed

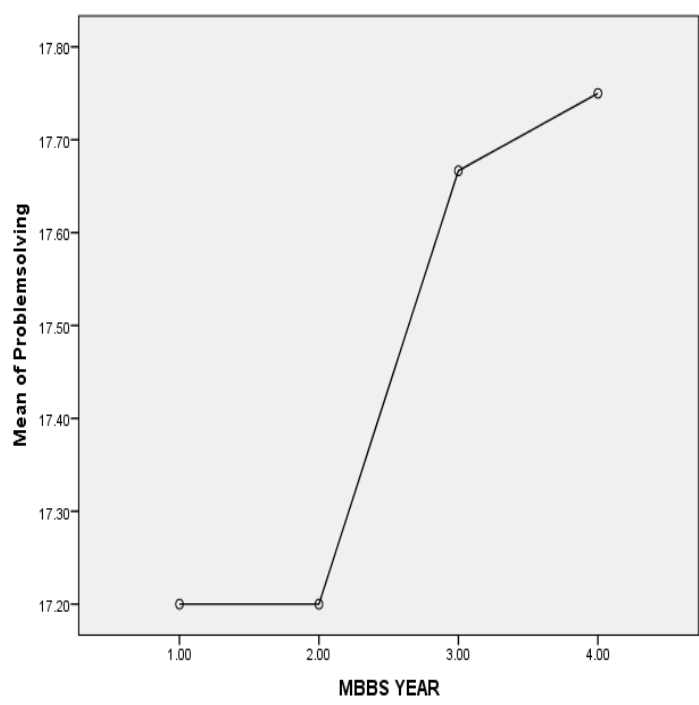

Figure 4: Problem Solving Coping Employed in different years of study 
Table 2: Type of Stressors among Medical Students

\begin{tabular}{lcc}
\hline Stressor & Mean & SD \\
\hline 1) Academic Related Stressor & & \\
$\quad$ (ARS) & & \\
& 2.72 & 1.06 \\
Tests/Examinations & 2.09 & 1.15 \\
Falling behind in reading schedule & 2.56 & 1.00 \\
Large amount of content to be learned & 2.60 & 1.13 \\
Lack of time to review what has been & & \\
learnt & 2.43 & 0.99 \\
Heavy workload & & \\
2) Social Related Stressor (SRS) & 1.73 & 1.14 \\
& & \\
Unable to answer questions from & 1.38 & 1.19 \\
patients & & \\
Talking to patients about personal & & \\
problems & & \\
Facing illness or death of patients & 1.97 \\
\hline 3) Group Activity Related Stressor &
\end{tabular}

\section{(GARS)}

Participation in class presentation

Need to do well (Imposed by others)

$1.40 \quad 1.16$

Feeling of incompetence

$1.83 \quad 1.23$

$1.74 \quad 1.29$

4) Intrapersonal Related Stressor (IRS)

$\begin{array}{lll}\text { Verbal or physical abuse by student(s) } & 1.38 & 1.20 \\ \text { Verbal or physical abuse by teacher(s) } & 1.58 & 1.25 \\ \begin{array}{l}\text { Verbal or physical abuse by } \\ \text { personnel(s) }\end{array} & 1.53 & 1.31 \\ \text { Conflict with teacher(s) } & 1.45 & 1.19\end{array}$

\begin{tabular}{lll}
\hline 5) $\quad \begin{array}{l}\text { Teaching and Learning Related } \\
\text { Stressor (TLRS) }\end{array}$ & \\
& & \\
& & \\
Not enough feedback from teacher(s) & 1.17 & 1.18 \\
Verbal or physical abuse by teacher(s) & 1.62 & 1.28 \\
Verbal or physical abuse by & 1.62 & 1.29 \\
personnel(s) & & \\
\hline 6) Drive Related Stressor (DRS) & & \\
$\quad$ Unwillingness to study medicine & 1.24 & 1.33 \\
Parental wish to study medicine & 1.28 & 1.37 \\
\hline SD = standard deviation
\end{tabular}

\section{Discussion}

Medical education in itself has a profound effect not only on the health of the student but also on the quality of life which is expected to change, demanding life style modifications and adaptations (24). This paradigm shift if not tackled properly can result in insufficiency in future clinical practice that will possibly affect patients and health of the community (23).

Stress encountered during medical education may lead to a plethora of detrimental consequences and sustained endurance of stress is injurious to health (25). On the contrary some researchers have recommended subsistence of

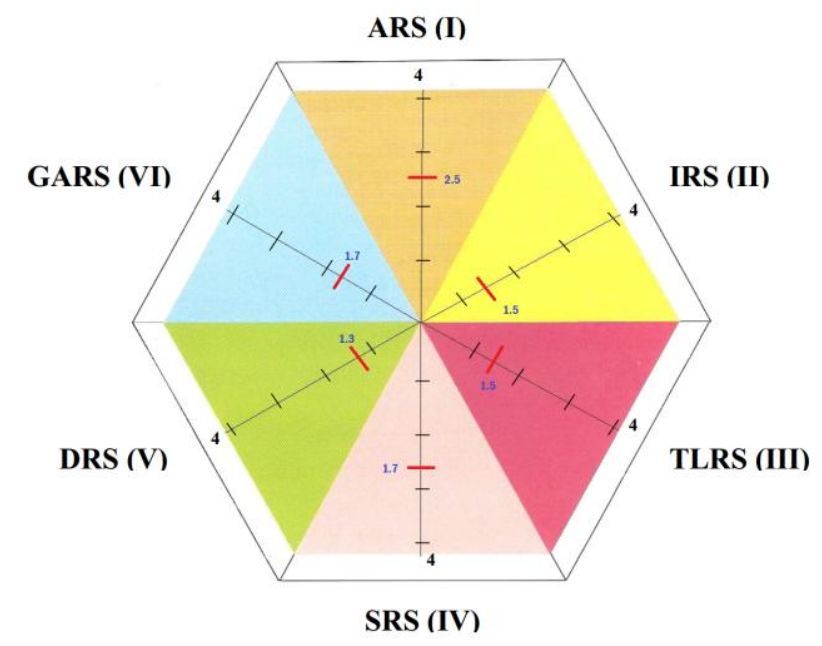

Figure 5: Overall stressors (Medical students, Ziauddin University)

Table 3: Mean scores of stressor domains

\begin{tabular}{llllll}
\hline Stressor: & Mean $\&$ SD & $1^{\text {st }}$ Year & $2^{\text {nd }}$ Year & $3^{\text {rd }}$ Year & $4^{\text {th }}$ Year \\
\hline (I) ARS & $2.48 \pm 0.82$ & 2.73 & 2.19 & 2.36 & 2.64 \\
(II) IRS & $1.48 \pm 1.06$ & 1.70 & 1.45 & 1.25 & 1.53 \\
(III) TLRS & $1.47 \pm 1.04$ & 1.47 & 1.37 & 1.35 & 1.47 \\
(IV) SRS & $1.69 \pm 0.96$ & 2.02 & 1.80 & 1.55 & 1.41 \\
(V) DRS & $1.26 \pm 1.19$ & 1.18 & 1.23 & 1.28 & 1.27 \\
(VI) GARS & $1.66 \pm 0.95$ & 1.76 & 1.66 & 1.43 & 1.66 \\
\hline
\end{tabular}

some stress for learning (11) and studies have even encountered some stress as advantageous as it may lead students to be more active, invigorated and creative (25). Burgeoning literature regarding stress during medical education has been seen in the last few decades as it is observed that medical students admitted making their study setting competitive thereby procreating a stressful environment $(11,26)$. As elicited by our results which are in line with previous findings that medical students dealt with a variety of stressors like work overload, time shortage and over expectations (27). In India $73 \%$ of students experienced stress during medical education (28), 63\% in Thailand 
underwent the same as measured by Thai Stress Test (29) and 57\% in Singapore. Similarly United Kingdom, Australia Malaysia and previous studies from Pakistan produced analogous results $(12,13,25,26)$.

When the most prevalent among the different types of stressors was assessed, our study pointed towards academic stressor. These results complemented earlier work done by Shah et al in Pakistan which had labeled academic examination as the biggest stressor. Studies conducted internationally also endorsing these findings $(12,26,31-34)$. The excess of findings all points towards vast course content and examinations and some of the studies specifically the one conducted in Sindh pointed towards time shortage $(19,35,36)$. Similar results were quoted from our study where course content, lack of time and examinations were associated with high stress values.

Contrary to the available literature interpersonal related and drive related stressors were found to be insignificant in our study $(29,30,37)$. International works have shown problem solving as a more delectable way of countering stress as affirmed by Sarason in his study (38). Wishful thinking strategy has shown to be less beneficial for coping stress which was acknowledged by another study conducted on graduated medical students (39). Our results give weight to existing data as problem solving coping was slightly utilized more than wishful thinking by students. Earlier reports, work done by Roy-Byrne et al and a study conducted in Pakistan showed cognate results $(12,40-41)$. The study conducted in Pakistan had shown $75 \%$ of medical students satisfied by arrogating coping mechanism to counter stress (12).

International work has exhibited that stressors show variation during different phases of medical education as inveterated by our study results $(6,42)$. Antagonist views were observed when Guthrie et al commended no association between year of study and stress (43). When different years of study were subject to stress, international studies proved that though pleonastic in nature each year has unique stressors Research conducted in UK and India showed first year as the most potential target for stress (11). Frequent examinations, workload, complexity and fatigue were the common stressors (44-45)

These findings were contrary to the one demonstrated in our study and others conducted in Malaysia, Thailand, India and Pakistan where higher stress was observed in third year and fourth year students $(12,19,29,46)$. Probably it is the transition from lecture based curriculum to direct patient care in third year that disposes this year to stressful impact (11).

The study faced few limitations. Generalizability of the study results is limited by the characteristic of the sample, which was recruited from a single public medical college. Despite assuring anonymity and confidentiality of their responses underreporting of diverse group of stressors and coping responses might be an issue. Lack of baseline results concerning mental status of students and assessment based on grades was another limitation. However the strengths of the present study cannot be ignored. Our high response rate was similar to work done globally (27). Utilization of a validated questionnaire was another strength. Like previous work our results has clinical importance concerning general health status and quality of student's life (8).

Jittery and aggressive physicians make erratic decisions that can lead to serious tribulations for the patients under their treatment (25). Though exams are a necessity for learning and encouraging students, yet they remain a major source of stress (30). From a students point of view some reckon exams as a burden, for others it is an instigation for learning (30). The stress acquiring nature of medical students is likely to linger in their professional life (47). From 1966 to 1999 over 600 articles have been documented on stress however merely 24 studies have been regarding interventions for stressors of medical students (48). Previous intervention studies have proven to be promising (49-51)

Medical schools should cater not only to medical content also to student lives. Proper time 
management can mitigate the heebie-jeebies inherent to many obligations of the course (52).

A structured orientation program that addresses expectation at each phase and how to cope with it, teaching self-care skills (52) peer education and counseling an approach highly successful in pedagogy (53) and structured time outs (25) Along with it genial faculty, students discussion groups to counter vast course demands, mentoring, psychological and pedagogical support are just some recommendations to ward off stressors (54). Cross sectional study did not permit us to assess the interactions between stressors and coping strategies over time, future longitudinal studies must take into account the complex and dynamic interactions of both. If students learn to face stressors rather than succumbing to its putative nature and take responsibility during medical education it is expected they take greater care of their own health and serve as a conduit to transfer preventive approach to patients (55).

\section{Conclusion}

Experiences in medical school are associated not only with personal and professional development, but also with psychological toxicity and a negative impact on student's quality of life. For student's lack of selfconfidence, seclusion and general personal neglect might have serious impact on their personal and social life. Adaptive and maladaptive skills developed in medical education may form the groundwork for future professional adjustment (56) multifarious obligations stemmed as stressors for medical students. Academic stressors were most potential causes of stress. Third year medical students had the greatest intensity of stress, followed by fourth year students. The least amount of stress was seen in first year students. Coping skills may be a useful intervention to mollify the pernicious effects of stress. Problem solving coping strategy was more effective as compared to wishful thinking. Our results speak volumes on frequency of stress in medical students and constitute significant material for program directors, teachers and students to reflect on. It directs the need for preserving and improving the health of medical students during this challenging phase of their lives, characterized by difficulties on one side with satisfaction of accomplishing goals on the other.

\section{Acknowledgement}

I owe a special thanks and gratitude to $\mathrm{Dr}$ Muhammad Saiful Bahri Yusoff and Ann-Marie Roy for all their assistance and allowing me to use their questionnaires.

\section{Reference}

1. World Health Organization (1994). The health of young people: A challenge and a promise. Geneva: WHO, Access on http://apps.who.int/iris/handle/10665/37353

2. Sherina MS, Lekhraj R, Nadarajan K. Prevalence of Emotional Disorder among Medical Students in a Malaysian University. Asia Pac Fam Med. 2003; 2:213-17.

3. Dahlin M, Joneborg N, Runeson Bo. Stress and Depression among Medical Students: A Cross Sectional Study. Med Educ, 2005; 39: 594-604.

4. Dyrbye LN, Thomas MR, Shanafelt TD. Medical Students Distress: Causes, Consequences, and Proposed Solutions. Mayo Clin Proc. 2005;80(12):1613-22

5. Aktekin M, Karaman T, Senol YY, Erdem S, Erengin H, Akaydin M. Anxiety, Depression and Stressful Life Events among Medical Students: A Prospective Study in Antalya, Turkey. Med Educ. 2001; 35(1):12-17.

6. Zaid ZA, Chan SC, Ho JJ. Emotional Disorders among Medical Students in a Malaysian Private Medical School. Singapore Med J. 2007; 48(10):895-99.

7. De Armond MM: A quality assurance program for a Mental Health Service. J Am Coll Health Assoc 1981, 30(3):139-40.

8. Chandrashekhar T Sreeramareddy, Pathiyil R Shankar, VS Binu, Chiranjoy Mukhopadhyay, Biswabina Ray et.al. Psychological morbidity, sources of stress and coping strategies among undergraduate medical students of Nepal. BMC Medical Education 2007; (doi: 10.1186/1472-6920-726): 7:26.

9. Niemi PM, Vainiomaki PT: Medical students' academic distress, coping and achievement strategies during the preclinical years. Teach Learn Med 1999, 11:125-34 
10. Kaplan HI, Saddock BJ. Learning Theory. In: Synopsis of Psychiatry: Behavioral Sciences/Clinical Psychiatry. 8th ed. Philadelphia: Lippincott Williams \& Wilkins. 2000;p.148-54

11. Linn BS, Zeppa R. Stress in Junior Medical Students: Relationship to Personality and Performance. J Med Educ. 1984; 59(1):712.

12. Shaikh BT, Kahloon A, Kazmi M, Khalid H, Nawaz K, Khan N, Khan S: Students, stress and coping strategies: a case of Pakistani medical school. Educ Health (Abingdon) 2004, 17:346-53.

13. Sherina MS, Rampal L, Kaneson N: Psychological stress among undergraduate medical students. Med J Malaysia 2004, 59:207-11.

14. Cohen JS, Patten S. Well-being in residency training: a survey examining resident physician satisfaction both within and outside of residency training and mental health in Alberta. BMC Med Educ 2005; 5: 21, 1-11.

15. Mundt, M.H. (1996). Peer interviewing: A student health survey on an urban campus. Journal of American College Health, 44, 187 $-192$.

16. Holahan, C. J., \& Moos, R. H. (1987). Risk, resistance, and psychological distress: A longitudinal analysis with adults and children. Journal of Abnormal Psychology, 96, 3 -13.

17. Government of Pakistan (2000). 1998 National Census Report. Islamabad: Population Census Organization, Statistics Division

18. Xiang, H. et al. (2000). Cigarette smoking amongst medical students in the Republic of China. Preview of Medicine, 29, 210-15.

19. Yusoff MSB. (2011a). A Confirmatory Factor Analysis Study on the Medical Student Stressor Questionnaire among Malaysian medical students. Educ Med J, 3(1). doi: 10.5959/eimj.3.1.2011.or5

20. Yee LY, Yusoff MSB. Prevalence and sources of stress among medical students in Universiti Sains Malaysia and Universiteit Maastricht. Educ Med J 2013; 5(4): 7:26.

21. Folkman, S., \& Lazarus, R. S. (1985). The Revised Ways of Coping [online]. San Francisco: University of California. Available from: http//www.caps.ucsf.edu./capsweb/pdfs/Way sofcoping.pdf.

22. Roy, A.M., 2003. Coursework stress in university students: Investigating problem solving coping, wishful thinking coping, anxiety and depression as predictors of coursework stress. United Kingdom (UK).

23. Yee LY, Yusoff MSB. Prevalence and sources of stress among medical students in Universiti Sains Malaysia and Universiteit Maastricht. J Med Educ 2013; 5(4): 7:26.

24. Tempski, P., Bellodi, P. L., Paro, H. B., Enns, S. C., Martins, M. A., \& Schraiber, L. B. (2012). What do medical students think about their quality of life? A qualitative study. BMC medical education, 12(1), 106.

25. Carter AO, Elzubeir M, Razzaq A, Revel YM, Townsend A. (2003). Health and lifestyle needs assessment of medical students in the United Arab Emirates. Medical Teacher, 25, 492-96.

26. Schwartz A.J, Black ER, Goldstein MG, Jozefowicz RF, Emmings, FG. Levels and Causes of stress among residents. J. Med. Educ. 62 (1987):744-53

27. Ko SM, Kua EH, Fones CSL. Stress and The Undergraduate, Singapore Med J. 1999; 40:627-30

28. Supe AN. A study of stress in medical students at Seth G.S. Medical College. J Postgrad Med 1998; 44:1-6.

29. Saipanish R: Stress among medical students in a Thai medical school. Med Teach 2003, 25:502-6.

30. Moffat KJ, McConnachie A, Ross S, Morrison JM: First year medical student stress and coping in a problem-based learning medical curriculum. Med Educ 2004, 38:482-91

31. Taylor, S., 1998. Coping Strategies. Research Network on Socioeconomic Status and Health. http://drtedzeff.com/tips/coping/

32. Shah M, Hasan S, Malik S, Sreeramareddy $\mathrm{C}$ : Perceived stress, sources and severity of stress among medical undergraduates in a Pakistani medical school. BMC Med Educ 2010, 10(1):2

33. Coburn DR, Jovaisas AV. "Perceived sources of stress among first year medical students" J Med Edu. 1975; 50:589-95

34. Kaufman DM, Day V, Mensink D. Stressors in Medical School: Relation to Curriculum Format and Year of Study. Teach Learn Med.1998; 10(3):188-194.

35. Baldassin S: Ansiedade e Depressão no Estudante de Medicina: Revisão de Estudos Brasileiros. Cadernos ABEM 2010, 6(6):1926.17

36. Shaikh, S., Shaikh, A. H., \& Magsi, I. (2010). Stress among medical students of 
university of interior Sindh. Medical Channel, 16(4)

37. Clark EJ, Rieker PP. Gender Differences in Relationships and Stress of Medical and Law Students. J Med Educ. 1986; 61(1):3240. 17

38. Sarason, I. G. (1984). Stress, anxiety, and cognitive interference: Reactions to tests. Journal of Personality and Social Psychology, 46, 929- 938. Cited in Bernstein, D. A., Penner, A., Clarke. Stewart, A., \& Roy, E. J. Psychology (6th ed). Boston New York: Houghton Mifflin Company.

39. Wolf TM, Faucett JM, Randall HM, Balson PM.. Graduating medical students' ratings of stresses, pleasures, and coping strategies.J Med Educ 1988; 63(8): 636-42.

40. Roy- Bryne, P. P., Vitaliano, P. P., Cowely, D. S., Luciano, G. B. S., Zheng, Y. \& Dunner, D. L. (1992). Coping in panic and major depressive disorder relative effects of symptom severity and diagnostic co morbidity. Journal of Nervous and Mental Disease, 180, 179-83.

41. Keniston K the Medical Student yale J. Biol. Med 39:346-358, 1967.

42. Gaensbaeur T.J and Mizner G.L Developmental stressors in Medical education Psychiatry 43:60-70 1980

43. Guthrie EA, Black D, Bagalkote H, Shaw C, Campbell M, Creed F. Psychological Stress and Burnout in Medical Students: A Fiveyear Prospective Longitudinal Study. $J R$ Soc Med. 1998; 91(5):237-43.

44. Vaz RF, Mbajiorgu EF, Acuda SW. A preliminary study of stress levels among first year medical student at university of Zimbabwe. Cent Afr J Med 1998; 44:214-9.

45. Mitchell RE, Matthews JR, Grandy TG, Lupo JV. The question of stress among firstyear medical students. J Med Educ 1983;58:367-72

46. Kumarswamy N, Ebigbo PO. "Stress among second year medical students - A comparative study" Indian J Clin Psychol. 1989; 16:21-23.

47. Firth-Cozens, J. (2001). Medical students stress. Medical Education, 35, 6-7. 9

48. Shapiro SL, Shapiro DE, Schwartz GER: Stress management in medical education: a review of the literature. Acad Med 2000, 75(7):748

49. Ball SE, Bax A: Self-care in Medical Education: Effectiveness of Health - Habits Interventions for First-Year Medical Students. Acad Med 2002, 77:911-17.
50. Tempski P, Perotta B, Pose RA, Vieira JE: A questionnaire on the quality of life of medical students. Med Educ 2009, 43:11071108

51. Holm M, Tyssen R, Stordal KI, Haver B: Self-development groups reduce medical school stress: a controlled intervention study. BMC Med Educ 2010, 10:23

52. Redwood SK, Pollak MH: Student-led stress management program for first-year medical students. Teach Learn Med 2007, 19:42-6,

53. Baudier, F., Bonnin, F. \& Michaud, C. (1997). Les groupes de pairs et la promotion de la sante'. La sante' des adolescents: Approche, soins, pre' vention. Laussane: Payot, Paris: Doin, Montre'al : Press de l'Universitaire, pp 94 - 99

54. Ball SE, Bax A: Self-care in Medical Education: Effectiveness of Health - Habits Interventions for First-Year Medical Students. Acad Med 2002, 77:911-917.

55. Toews, J. A., Lockyer, J. M., Dobson, D. J., \& Brownell, A. K. (1993). Stress among residents, medical students, and graduate science $(\mathrm{MSc} / \mathrm{PhD})$ students.Academic Medicine, 68(10), S46-8.

56. Bok D. Needed A New way to train doctors Harvard Rev (86) 1984 32-43 70-71 